Research Article

\title{
Structural Properties of Concrete Materials Containing RoadCem
}

\author{
Niall Holmes \\ School of Civil \& Structural Engineering, Dublin Institute of Technology, Bolton Street, Dublin 1, Ireland \\ Correspondence should be addressed to Niall Holmes; niall.holmes@dit.ie
}

Received 16 April 2015; Accepted 3 June 2015

Academic Editor: F. Pacheco-Torgal

Copyright ( 2015 Niall Holmes. This is an open access article distributed under the Creative Commons Attribution License, which permits unrestricted use, distribution, and reproduction in any medium, provided the original work is properly cited.

\begin{abstract}
This paper presents findings from a preliminary study to assess the structural and material properties of a nonstandard, concrete type mix containing RoadCem, a traditional soil stabilising additive. Two different mixes determined the effect of adding RoadCem in terms of compressive and flexural strengths, breaking strain, thermal expansion and contraction behaviour, permeability using a falling head, and Young's modulus. RoadCem is a fine powder containing alkali metals and synthetic zeolites which are complemented with a complex activator. RoadCem modifies the dynamics and chemistry of cement hydration by enhancing the crystallisation process and forming longer needle crystalline structures. It reduces the heat of hydration with an early strength development. Varying the volume in the mix varies the viscosity and alters curing times while maintaining the water cement ratio. The results from this study have shown a modest increase in compressive strength and Young's modulus with improvements in thermal performance, particularly at low temperatures. The flexural strength of the two mixes was similar with a much reduced permeability in the RoadCem mix. The results demonstrate the improved performance of concrete incorporating RoadCem but further improvements are possible by using a better graded aggregate and controlling the maximum dry density and moisture contents.
\end{abstract}

\section{Introduction}

RoadCem is a fine powered cement-based soil stabiliser used on earthworks, motorway, and hydraulic engineering projects [1]. Research has shown [2-6] that soils stabilised with cement-based additives have superior mechanical properties than those without. Depending on the soil or application, the quantity of RoadCem ranges from 1 to $2.8 \mathrm{~kg}$ per cubic meter [1-7]. Foundation layers prepared with RoadCem vary in thickness from 200 to $400 \mathrm{~mm}$ where a thinner wearing course layer (bitumen emulsion, dense asphalt, etc.) can be constructed on top.

By combining with the soil, the addition of RoadCem changes the mineralogical structure leading to a strong, durable crystalline structure which is fibrous in nature $[1,7$, 8]. RoadCem tends to wrap the fibres rather than glue and then forms a dense matrix. This has shown to provide better thermal resistance, flexural strengths, and fatigue properties $[6,9]$. Examples of RoadCem as a soil stabiliser include a ring road around Houston Texas in the United States, an oil drilling platform in the Amazon basin, a $70 \mathrm{~km}$ highway in Mexico, and a runway in the Brno Airport in the Czech Republic to name a few [7].

Previous work into the addition of cement-based soil stabilisers in concrete investigated the effect of variables including compaction friction, specimen size, compaction delay, and curing conditions encountered in laboratory environments [1-6, 9-11]. RoadCem is generally in dosages from 0.18 to $5 \mathrm{~kg}$ per cubic meter when mixed with concrete [1]. A minimum dosage of $50 \mathrm{~g}$ is recommended by the manufacturers [7]. Unreinforced roller compacted concrete (RCC) produces a low workability mix and has been used [12-17] for roads, car parks, and large slabs. This material has shown to be strong in compression but weak in tension, due to shrinkage during ongoing hydration and changes in ambient temperature and internal moisture.

Little research has been undertaken to assess the improvements RoadCem can make to the structural properties of concrete. Its addition reduces the heat production during hydration and limits the need for additional additives [18]. 
TABLE 1: Mix proportions.

\begin{tabular}{lccccc}
\hline \multirow{2}{*}{ Mix ID } & \multicolumn{5}{c}{ Mass of ingredients $\left(\mathrm{kg} / \mathrm{m}^{3}\right)$} \\
& CEM I & Water & FA & CA & RoadCem \\
\hline 1 & 19.4 & 11.7 & 56.3 & 227 & 0 \\
2 & 76.7 & 46 & 222.1 & 894.7 & 0.767 \\
\hline
\end{tabular}

FA: fine aggregate, CA: course aggregate.

One application of RoadCem in concrete is thin hybrid layers (THL) which is a pavement product constructed underneath an asphalt or bitumen surface layer $[14,19,20]$. THL materials are flexible with a high dynamic elastic modulus, compressive and flexural strengths, and breaking strain without the problems associated with standard concretes, including shrinkage, rate of curing, and frequency of joints, thinner with a faster time for traffic loading. Course quarry aggregate material, which is often clay-laden and unsuitable for blending with cement, can be incorporated into a THL with significant savings compared to standard pavement designs. However, the THL mix must be assessed for strength (compressive and flexural), thermal properties, and water permeability. This must be achieved while maintaining an appropriate $\mathrm{w} / \mathrm{c}$ ratio to achieve full hydration with full compaction for an enhanced THL service life.

In order to assess the effect of RoadCem in concrete and its potential as a RCC or THL, an experimental investigation was carried out at the Dublin Institute of Technology, Ireland. As RoadCem is known to produce a zero-slump material, it was decided to study the effect of the additive on the structural (compressive strength, flexural strengths, and Young's modulus), thermal (freezing and thawing), and durable (permeability) performance of different mixes. The samples included a plain CEM I mix and another containing RoadCem. The results of this study are reported and discussed in this paper and the findings show the potential of the additive to improve the structural properties and thermal performance while offering suggestions to improve the permeability.

\section{Experimental Programme}

2.1. Mix Proportions. Two mixes were cast for this study, plain incorporating only CEM I cement and a second with the RoadCem additive with $1 \%$ by weight of cement both with a fixed w/c ratio of 0.60 . The cement content of the plain and the RoadCem concretes was 19.4 and $76.7 \mathrm{~kg} / \mathrm{m}^{3}$, respectively. The cement volume increased in the second mix to account for the minimum PowerCem requirement of $50 \mathrm{~g}$ [7]. These mixes are based on RCC requirements which normally contain larger shaped aggregates with flexural strength deemed more important.

A summary of the mixes cast and details are shown in Table 1.

2.2. Materials. CEM I (Strength Class $42.5 \mathrm{~N}$ ) cement complying with EN 197-1, Cement: Composition, Specifications and Conformity Criteria for Common Cements [21] was used as the cementitious material. The fine and coarse aggregates were obtained from local sources in Ireland. The fine aggregate was medium-graded sand and the coarse aggregate was uncrushed and unwashed with a maximum size of $14 \mathrm{~mm}$. Before mixing, the water absorption of the fine aggregates was determined and the water added to the mixes was adjusted accordingly to cater for this. Each mix had a volume of $0.075 \mathrm{~m}^{3}$ including $20 \%$ for wastage.

2.3. Preparation of Samples. The mixes were manufactured using a pan mixer with six $150 \times 150 \times 150 \mathrm{~mm}^{3}$ cubes, three $100 \times 100 \times 500 \mathrm{~mm}$ long beams, six $75 \times 75 \times 285 \mathrm{~mm}$ long prisms, and four $100 \mathrm{~mm}$ diameter $\times 130 \mathrm{~mm}$ long cylinders cast.

After mixing, the materials were poured in $50 \mathrm{~mm}$ thick layers, into the moulds with each layer vibrated on a vibrating table for a time. However, it was observed that this did not adequately compact the concrete so a jack hammer compactor rammer was used with a $100 \times 100 \mathrm{~mm}^{2}$ tamping plate connection. Curing was provided by placing a polythene sheet over the specimens for 24 hours to trap moisture that evaporates from the surface. Following demoulding, the samples were placed in water in a curing tank at $20( \pm 1)^{\circ} \mathrm{C}$ until testing.

\subsection{Tests Carried Out}

2.4.1. Compressive Strength. The compressive strength was determined by crushing three $150 \mathrm{~mm}$ cubes at 7 and 28 days for each mix in accordance with EN 12390-3 for testing hardened concrete [22].

2.4.2. Flexural Strength and Breaking Strain. The flexural strength was determined by breaking three $100 \times 100 \times$ $500 \mathrm{~mm}$ long beams at 28 days for each mix in accordance with BS 1881 Testing hardened concrete [23]. The tensile strength of the samples was determined using a 1/3rd point load test, as shown in Figure 1. The sample is supported at each end and a vertical load is applied at midpoint until fracture. The tensile strength $\left(\mathrm{N} / \mathrm{mm}^{2}\right)$ is calculated using (1), where $P$ is the load applied $(\mathrm{N}), l$ is the length between supports $(\mathrm{mm})$, $w$ is the width of the sample ( $\mathrm{mm})$, and $h$ is the thickness ( $\mathrm{mm})$. The flexural strain was also determined by attaching a $5 \mathrm{~mm}$ long Tokyo Sokki Kenkyujo strain gauge type YFLA with a gauge factor of $2.10 \pm 2 \%$ to the sides of the beam and monitored under load. Consider

$$
\sigma=\frac{1.5 P l}{w h^{2}}
$$

2.4.3. Young's Modulus. Young's modulus was determined using the $150 \mathrm{~mm}$ cubes at 28 days. The cubes were chosen as a better bond between the strain gauges ( $5 \mathrm{~mm}$ long Tokyo Sokki Kenkyujo strain gauge type YFLA with a gauge factor of $2.10 \pm 2 \%$ ) and the concrete is possible. The cubes were loaded up to $1 / 3$ of the failure strength, repeated three times with the slope of the stress-strain graph under load in the third cycle 


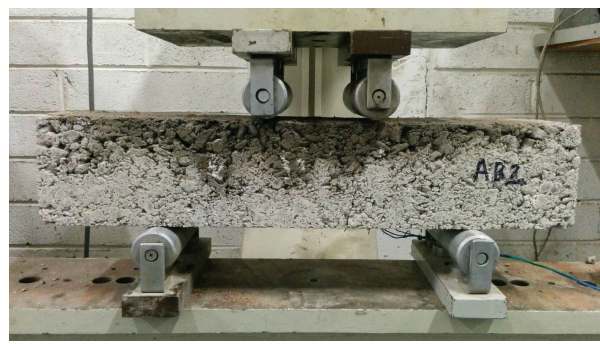

(a)

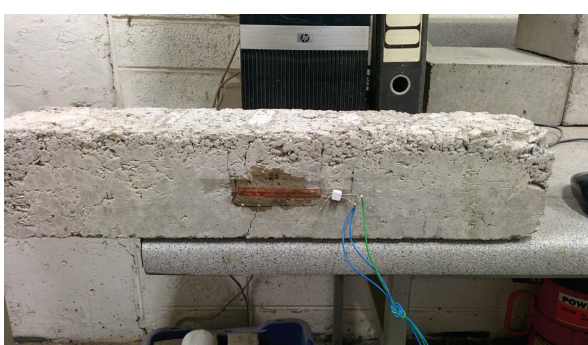

(b)

FIGURE 1: Flexural beam tests (a) during test and (b) with a strain gauge attached.

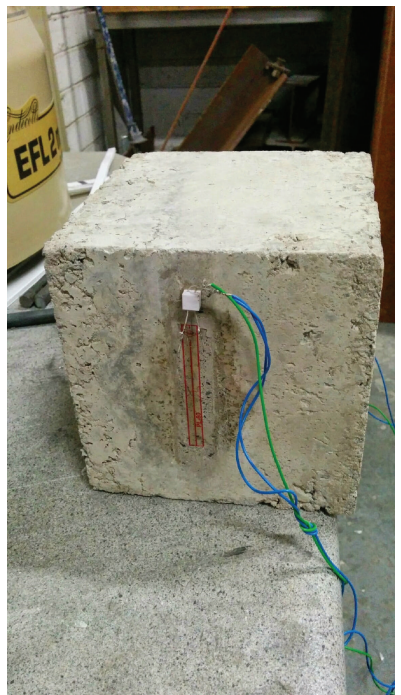

Figure 2: Cube with strain gauge attached to determine Young's modulus.

used for calculating Young's modulus. The concrete setup prior to testing is shown in Figure 2.

2.4.4. Thermal Analysis. The thermal analysis was carried out on the $75 \times 75 \times 285 \mathrm{~mm}$ prisms by placing in a heater and freezer at $80^{\circ} \mathrm{C}$ and $-15^{\circ} \mathrm{C}$, respectively, for 24 hours at 28 days old. The change in length was determined using the apparatus shown in Figure 3. The prisms used for the thermal analysis were also assessed for their flexural strengths (breaking strain was not recorded) immediately after measurement using the apparatus in Figure 3.

2.4.5. Falling Head Permeability. The coefficient of permeability of the samples was determined using the falling head apparatus shown in Figure 4 at 28 days. This test suits impermeable materials like concrete as the rate of flow through the material is slow and provides a more accurate result. By manipulating Darcy's Law, (2) below is used to determine the coefficient of permeability $(k)$ for the samples where $a$ is the standpipe cross-sectional area $\left(\mathrm{mm}^{2}\right), L$ is the length of the sample (mm), $h_{1}$ and $h_{2}$ are the initial and final head of water $(\mathrm{mm}), A$ is the cross-sectional diameter of the sample $\left(\mathrm{mm}^{2}\right)$, and $\Delta t$ is the duration of the test (sec). At least 4 tests were performed for each mix. Consider

$$
k=\frac{a L \ln \left(h_{1} / h_{2}\right)}{A \Delta t} .
$$

Each sample was fully saturated before testing to insure no absorption took place. After the sample was inserted, the tank was filled and a back pressure was applied to the system to remove any air locks. Water was allowed to flow into the pipe and up the three standpipes (Figure 4) which was then cut off using a clamp. The standpipes were levelled to an equal head above the system and each standpipes value was closed with only that for the change in head $(8 \mathrm{~mm}$ diameter, a) left open. The time taken for the water head to drop from a known starting height $\left(h_{1}\right)$ to the finish height $\left(h_{2}\right)$ was recorded.

\section{Results and Discussion}

3.1. Compressive Strength. The compressive strength results at 7 and 28 days are presented in Figure 5. As shown, the compressive strength is greater for the RoadCem samples at both ages. The strengths are low if compared with standard concretes and are due to two reasons.

Firstly, the cement content was low. This is a feature of RCC which prioritises flexural above compressive strength. While the amount of cement in the RoadCem is higher, the w/c ratio of 0.6 was maintained and the other constituents of the mix were also maintained. Secondly, the aggregate used was low grade with insufficient fines (passing a $63 \mu \mathrm{m}$ sieve) and excessive course (14 $\mathrm{mm}$ diameter). These were chosen as THL which are often constructed with soil stabilised with RoadCem making the design cost effective. However, in concrete, these savings have an impact of the compressive strength. Results would be improved using a better graded aggregate corresponding with a Fuller-Thompson grading curve [24]. This would also improve the performance for RCC constructed below an asphalt surface course. Secondly, while the fine aggregate was dried, the course aggregate was not. Drying the aggregates and using Proctor analysis to control the maximum dry density and moisture content would yield further improvements.

3.2. Flexural Strength. The flexural strength of the two mixes at 28 days is shown in Figure 6. As may be seen, Mix 1 is slightly higher which has been reported previously. One of the 


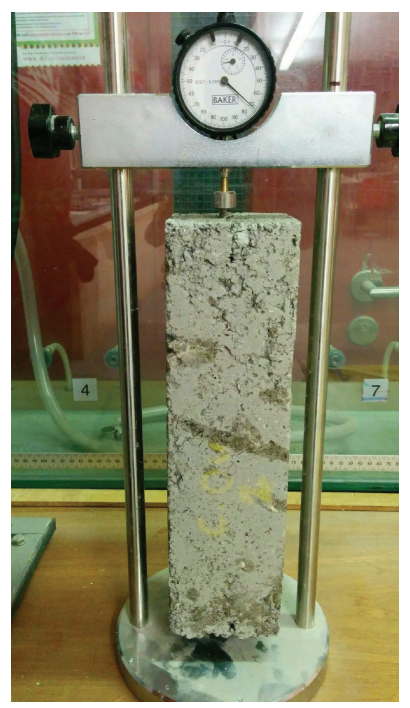

(a)

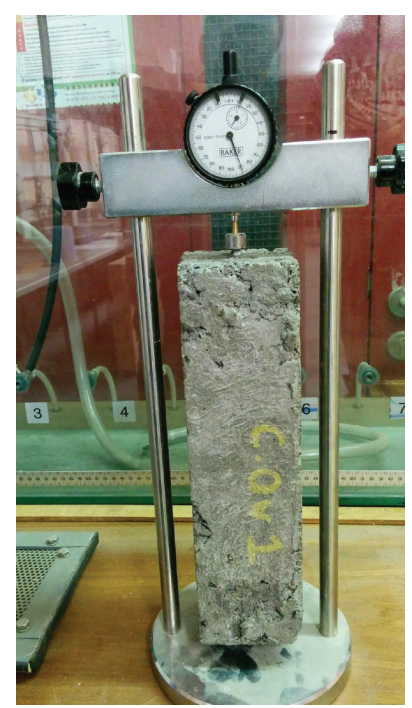

(b)

FIgURE 3: Sample prisms undergoing thermal (a) expansion and (b) contraction.

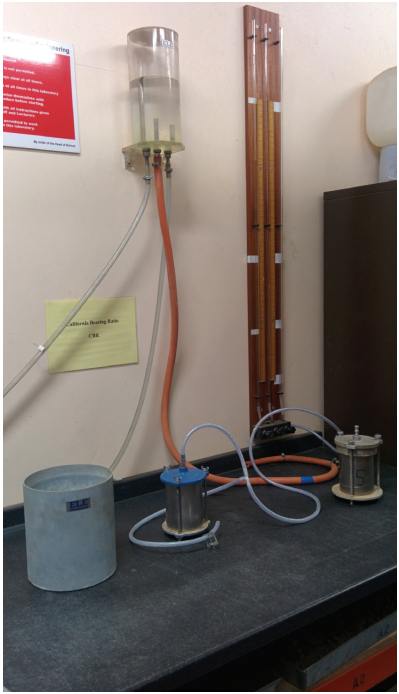

(a)

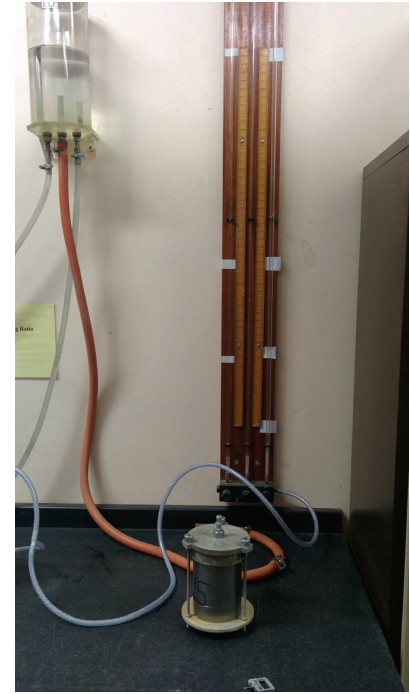

(b)

FIGURE 4: Samples undergoing the falling head permeability test.

requirements of THL is flexibility with low shrinkage [25-28]. The results here show that the flexural strength of RoadCem concrete is slightly lower than the plain mix. Using a better graded aggregate with better control of the moisture content, as discussed above, would increase the flexural strength.

Flexural strengths of concrete are typically $10 \%$ of the compressive. From Figure 6, it can be seen that the flexural strengths here are much greater, almost 20 and $26 \%$ for the RoadCem and plain mix at 28 days.

3.3. Breaking Strain. The flexural strain results are shown in Figures $7(\mathrm{a})-7(\mathrm{f})$. The rate of strain increase in the plain concrete samples (Figures $7(\mathrm{a})-7(\mathrm{c})$ ) appears to be more rapid and sharp. However, the material appears to yield first with a small increase in load until ultimate failure. For instance, yield strengths of 8,10 , and $10 \mathrm{kN}$ correspond with a yield strain of approximately 140,125 , and $180 \mu$ s. Upon further loading $(1-2 \mathrm{kN})$, failure occurs with significantly higher strains.

The results show the rate of strain increase during loading for the RoadCem (Figures 7(d)-7(f)) is linear up to the point of failure with no obvious yield point. As may be seen, for the plain mix, the ultimate failure load varies between 9 and $14 \mathrm{kN}$ with corresponding strains of 130-160 $\mu$ s approximately.

The results indicate that the plain mix is more flexible with yielding occurring before ultimate failure where the RoadCem samples sustain the load until breaking [29]. This 


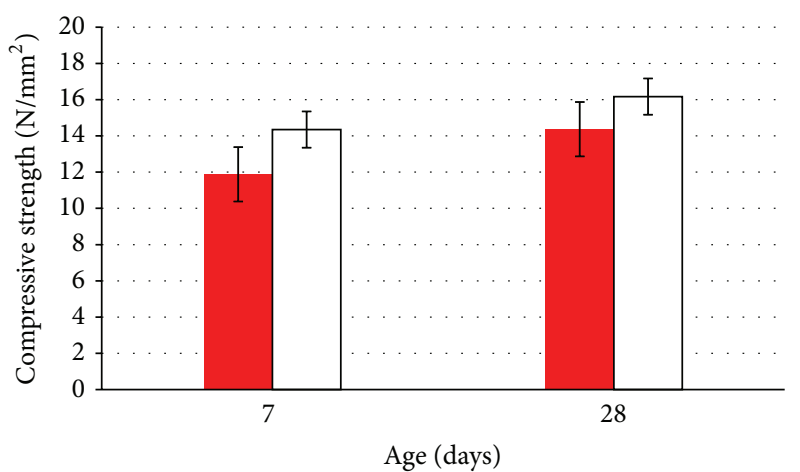

- Plain concrete

RoadCem

FIGURE 5: Compressive strength results.

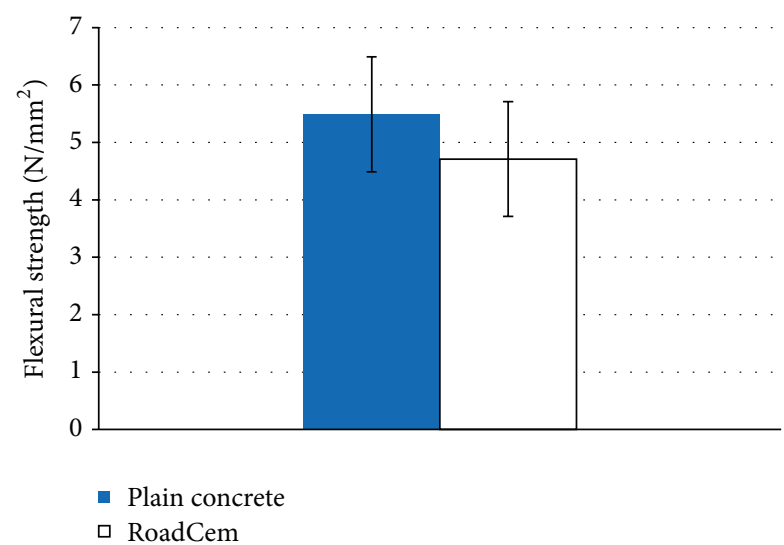

FIGURE 6: Flexural strength results.

corresponds with the slight higher flexural strengths seen in Figure 6.

3.4. Young's Modulus. Young's modulus of the plain and RoadCem concrete is shown in Figure 8 following the procedure set out above. The results demonstrate that the RoadCem mix is slightly stiffer than the plain which corresponds with the flexural strength and breaking strain findings. Due to the confinement of cubes, the value of $E$ can be reduced unlike cylinders, which permits a state of uniaxial compressive stress. To determine the accuracy of the values obtained, a comparison was made with the method outlined in Eurocode 2 [30] to calculate $E$ using the compressive strength. In (3), $E_{\mathrm{cm}}(t)$ is the secant modulus of elasticity at $t$ days, $f_{\mathrm{cm}}$ is the mean compressive strength at 28 days using Table 3.1 of Eurocode 2, $f_{\mathrm{cm}}(t)$ is the mean compressive strength at an age of $t$ days, and $E_{\mathrm{cm}}$ is the secant value for the modulus of elasticity $\left(0<\sigma_{c}<0.4 f_{\mathrm{cm}}\right)$ and can range between 0.3 and $0.4 f_{\mathrm{cm}}$ [31]:

$$
E_{\mathrm{cm}}(t)=\left(\frac{f_{\mathrm{cm}}(t)}{f_{\mathrm{cm}}}\right)^{0.3} E_{\mathrm{cm}}
$$

TABLE 2: Comparison of $E$ values at 28 days.

\begin{tabular}{lccc}
\hline \multicolumn{2}{c}{ Plain mix } & \multicolumn{2}{c}{ PowerCem mix } \\
$\begin{array}{l}\text { Measured } \\
\left(\mathrm{N} / \mathrm{mm}^{2}\right)\end{array}$ & $\begin{array}{c}\text { Calculated } \\
\left(\mathrm{N} / \mathrm{mm}^{2}\right)\end{array}$ & $\begin{array}{c}\text { Measured } \\
\left(\mathrm{N} / \mathrm{mm}^{2}\right)\end{array}$ & $\begin{array}{c}\text { Calculated } \\
\left(\mathrm{N} / \mathrm{mm}^{2}\right)\end{array}$ \\
\hline 4.7 & 4.8 & 5.3 & 5.7 \\
\hline
\end{tabular}

TABLE 3: Changes in length due to heating.

\begin{tabular}{lccc}
\hline \multicolumn{2}{c}{ Plain concrete } & \multicolumn{2}{c}{ RoadCem concrete } \\
\multicolumn{2}{c}{ Oven at $80^{\circ} \mathrm{C}$ for $24 \mathrm{hrs}$} & \multicolumn{2}{c}{ Oven at $80^{\circ} \mathrm{C}$ for $24 \mathrm{hrs}$} \\
Sample number & $\Delta L(\mathrm{~mm})$ & Sample number & $\Delta L(\mathrm{~mm})$ \\
\hline 1 & +0.002 & 1 & +0.11 \\
2 & +0.137 & 2 & +0.101 \\
3 & 0 & 3 & +0.002 \\
\hline
\end{tabular}

TABLE 4: Changes in length due to cooling.

\begin{tabular}{|c|c|c|c|}
\hline \multirow{2}{*}{\multicolumn{2}{|c|}{$\begin{array}{c}\text { Plain concrete } \\
\text { Oven at }-15^{\circ} \mathrm{C} \text { for } 24 \mathrm{hrs}\end{array}$}} & \multirow{2}{*}{\multicolumn{2}{|c|}{$\begin{array}{c}\text { RoadCem concrete } \\
\text { Oven at }-15^{\circ} \mathrm{C} \text { for } 24 \mathrm{hrs}\end{array}$}} \\
\hline & & & \\
\hline Sample number & $\Delta L(\mathrm{~mm})$ & Sample number & $\Delta L(\mathrm{~mm})$ \\
\hline 1 & -1.653 & 1 & -0.005 \\
\hline 2 & +0.029 & 2 & -0.001 \\
\hline 3 & -0.249 & 3 & -0.003 \\
\hline
\end{tabular}

Table 2 shows the comparison between the $E$ values determined experimentally and using (3) at 28 days with $E_{\mathrm{cm}}=$ $0.38 f_{\mathrm{cm}}$ and $f_{\mathrm{cm}}=20 \mathrm{~N} / \mathrm{mm}^{2}$ (Eurocode 2, Table 3.1). As may be seen, the measured and calculated values for $E$ for both samples are similar which confirms the suitability of the cubes to determine $E$ experimentally.

3.5. Thermal Analysis: Heating and Cooling. The results of the thermal analysis are shown in Tables 3 and 4 and demonstrate minimal expansion and contraction with very little difference between the two materials. However, the RoadCem concrete appears not as susceptible to contraction due to low temperatures. This is an important finding for both THL and RCC as they would be subjected to similar extremes of temperature variation. The results indicate that additional spacing between joints would be appropriate as both materials exhibit no significant expansion or contraction which corresponds with previous work in this area [32, 33].

3.6. Thermal Analysis: Flexural Strength. Figure 9 shows the flexural strength of the prisms following 24 hours in the oven and freezer. As may be seen, the flexural strength is higher in the RoadCem mix demonstrating that it is less susceptible to environmental conditions than its counterpart [33-38]. The flexural strength of both samples is lower at higher temperatures compared with Figure 7 and approximately half at lower temperatures. The results demonstrate that the flexural rigidity of the RoadCem sample is improved under heating and cooling. 


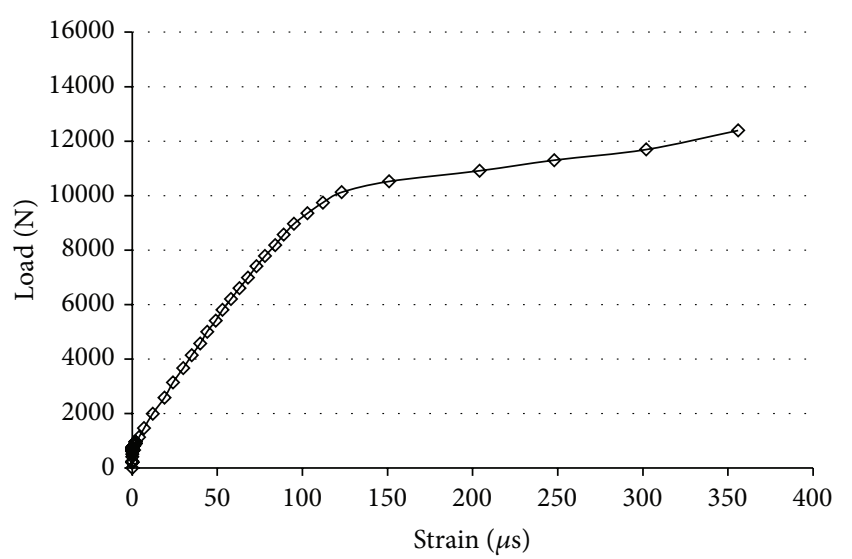

(a)

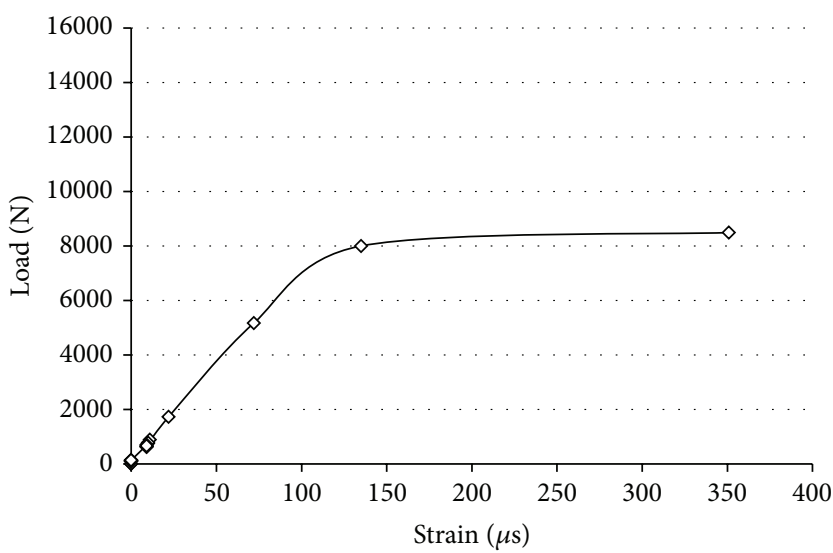

(c)

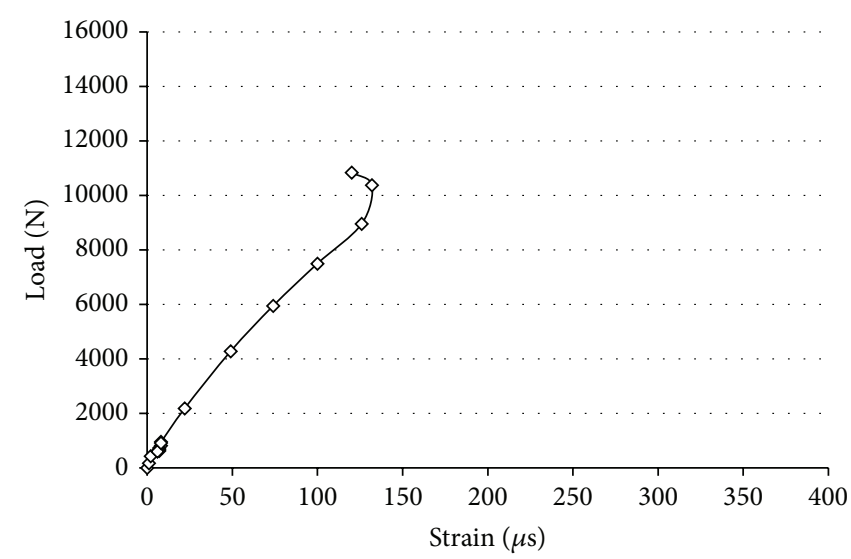

(e)

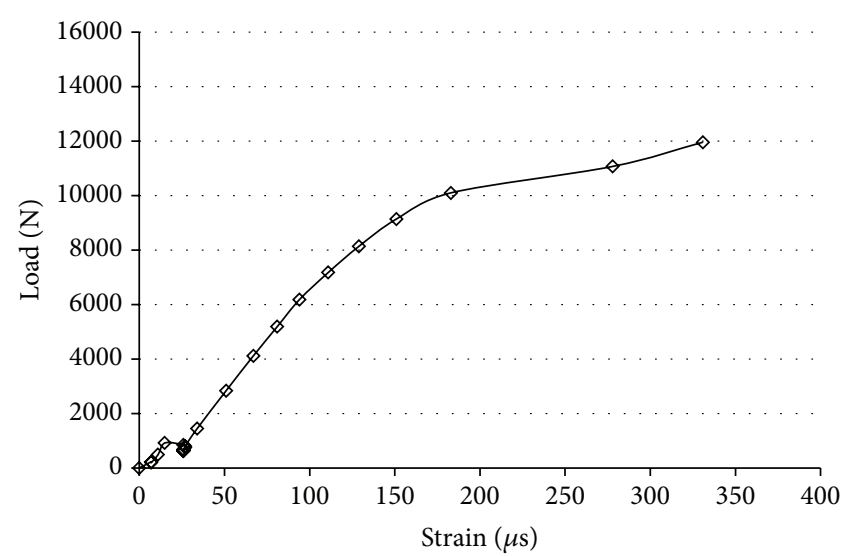

(b)

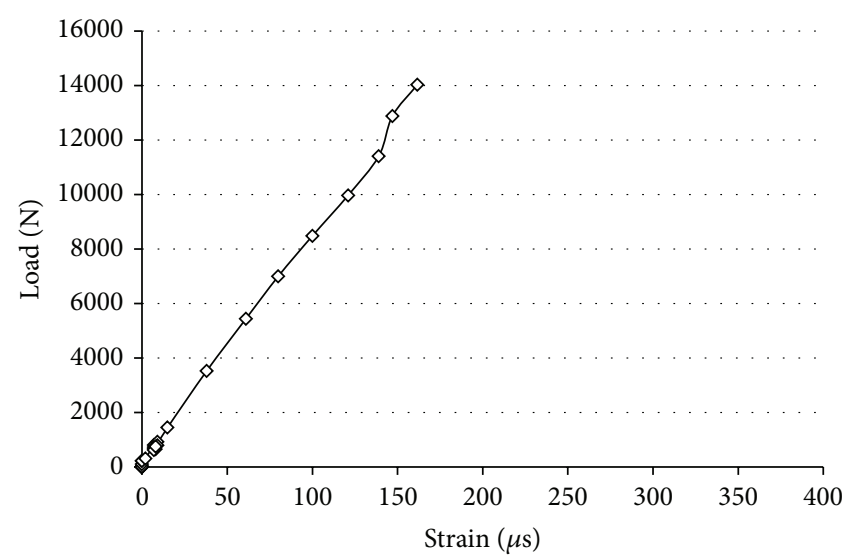

(d)

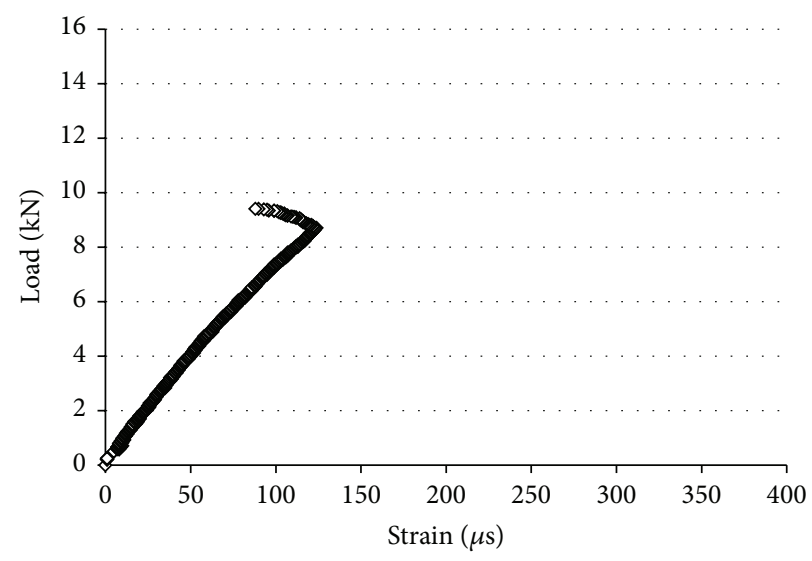

(f)

FIGURE 7: Flexural strain readings.

3.7. Permeability. The permeability results are shown in Figure 10. Both mixes show a decrease in permeability (increase in impermeability) over time. The permeability of the plain sample is marginally better than RoadCem. Both materials show poor impermeability performance [39] but increasing the fines content and using a more graded aggregate in both mixes would help improve the impermeability. Also, the course aggregates were unwashed so the ability of hydration products to bind and decrease the open pore structure would be affected.

\section{Conclusions}

On the basis of the various investigations carried out to assess the performance of cementitious materials containing 


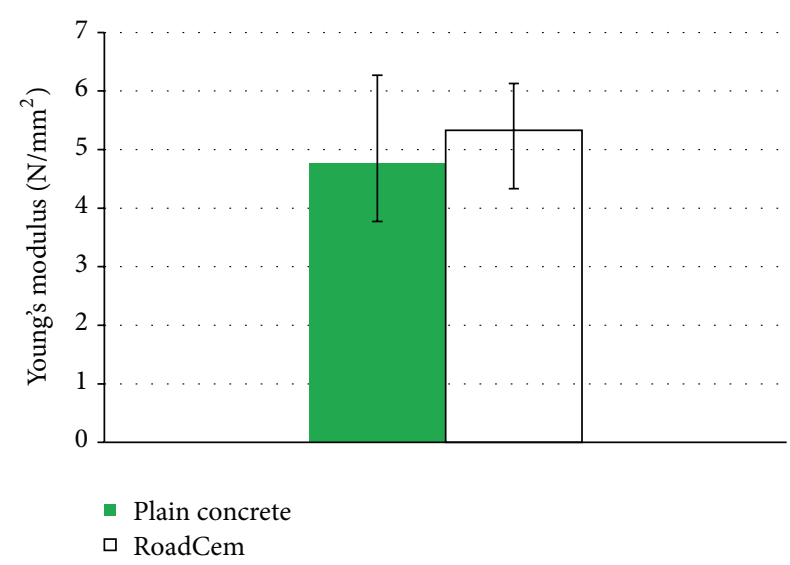

FIGURE 8: Young's modulus results.

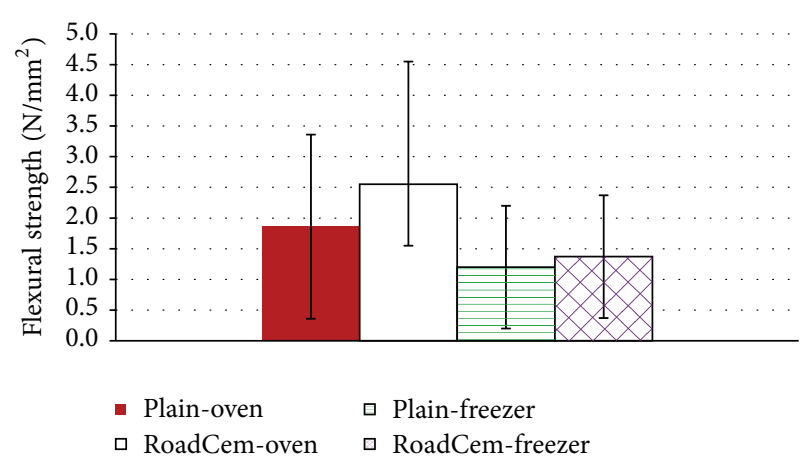

FIGURE 9: Flexural strength results following thermal analysis.

the RoadCem additive, the following conclusions have been drawn.

(1) The compressive strength was shown to increase with the addition of RoadCem compared with the plain mix. The flexural strengths and rates of strain increase are similar in both. There is a slight increase in Young's modulus in the RoadCem sample which is consistent with the flexural strengths and increase in strain rates during loading.

(2) The permeability of the RoadCem mix was noticeably less than the plain sample due to the uneven distribution of aggregates which created an open pore structure.

(3) The thermal performance of the RoadCem mix is much improved, particularly at low temperatures compared with the plain mix. The flexural strength of RoadCem following heating and cooling is also improved.

(4) Improvements in the results would be expected if a better graded aggregate was used corresponding with a Fuller-Thompson grading curve with sufficient fines passing a $63 \mu \mathrm{m}$ sieve. Better shaped aggregates would also improve the compressive and flexural strength, impermeability, and Young's modulus, particularly for roller compacted concrete and THL used in base materials below surface courses.

(5) As shown above, drying the aggregates and using a Proctor analysis to control the maximum dry density and moisture content would also yield improvements.

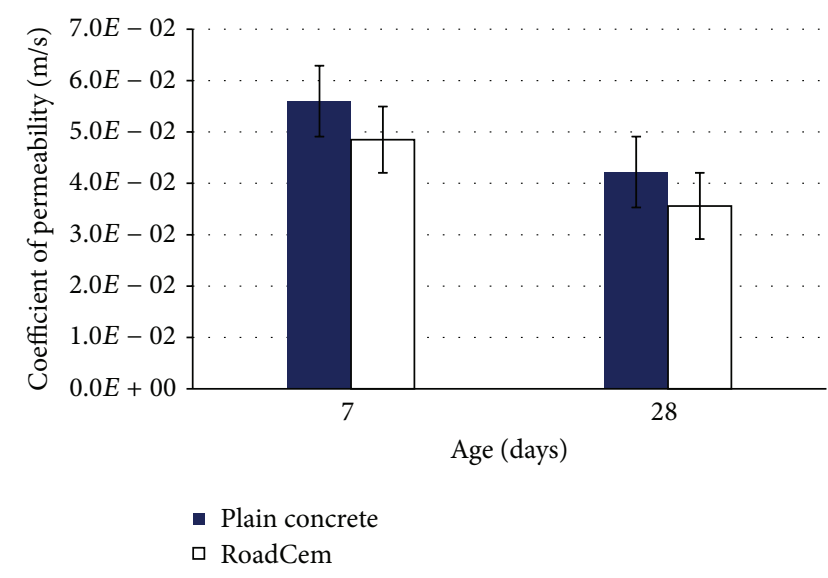

FIgURE 10: Coefficient of permeability results.

\section{Conflict of Interests}

The author declares that there is no conflict of interests regarding the publication of this paper.

\section{Acknowledgments}

The author wishes to acknowledge the funding provided by Invest NI Innovation Voucher programme which provided the financial support for this work. The author also thanks the technical support and the facilities of the School of Civil \& Structural Engineering in DIT Bolton Street and gratefully acknowledges Turley Brothers Ltd.

\section{References}

[1] P. Wu, "Cement-bound road base materials," Report 7-11-218-1, Delft University of Technology, PowerCem Technologies, Delft, The Netherlands, 2011.

[2] P. Sherwood, Soil Stabilization with Cement and Lime, HMSO, London, UK, 1993.

[3] D. J. Maclean, P. J. M. Robinson, and S. B. Webb, "An investigation of the stabilization of heavy clay soil with cement for road base construction," Roads and Road Construction, vol. 30, no. 358, pp. 287-292, 1952.

[4] M. S. Kersten, Soil Stabilization with Portland Cement, National Academy of Sciences National Research Council, 1961.

[5] Unified Facilities Criteria, Soil Stabilization for Pavements, United States Army Corps of Engineers, 2004.

[6] D. N. Little, Handbook for Stabilization of Pavement Subgrades and Base Courses with Lime, Kendall/Hunt Publishing, Dubuque, Iowa, USA, 1995.

[7] PowerCem Technologies, "Innovations for better solutionsRoadCem," 2015, http://www.powercem.com/en/roadcem.html.

[8] J. P. Milburn and R. L. Parsons, "P.E. Performance of soil stabilization agents," Report No. K-TRAN: KU-01-8, Kansas State University, 2004.

[9] TRH14, Guidelines for Road Construction Materials, 1985, http://www.scribd.com/doc/74783215/TRH14-1985-Guidelinesfor-Road-Construction-Materials\#scribd. 
[10] R. N. Yong and V. R. Ouhadi, "Experimental study on instability of bases on natural and lime/cement-stabilized clayey soils," Applied Clay Science, vol. 35, no. 3-4, pp. 238-249, 2007.

[11] S. Bnattacharja and J. I. Bhatry, Comparative Performance of Portland Cement and Lime Stabilization of Moderate to High Plasticity Clay Soils, RD125 PCA Research \& Development Bulletin, 2003, http://www.cement.org/docs/default-source/thpaving-pdfs/soil_cement/rd125-comp-perf-of-pc-and-limestabilization-of-mod-to-high-plasticity-clay-soils.pdf?sfvrsn=4.

[12] D. Croney, The Design and Performance of Road pavements, Transport and Road Resarech Laboratory, London, UK, 1977.

[13] Portland Cement Association, Reflective Cracking in Cement Stabilized Pavements, Portland Cement Association, Skokie, Ill, USA, 2003.

[14] J. Kennedy, Cement-Bound Materials for Sub-Bases and Road Bases: Material Selection and Mix Design, Construction and Control Testing, Cement and Concrete Association, Slough, UK, 1983.

[15] W. S. Adaska, "Roller-compacted concrete (RCC)," 2006, http://www.cement.org/think-harder-concrete-/paving/rollercompacted-concrete-\%28rcc\%29.

[16] L. Donald and J. W. Basham, Soil Stabilization for Pavements, United States Army Corps of Engineers, 1994.

[17] Portland Cement Association, Properties and Uses of CementModified Soil, 2003, http://www.cement.org/think-harderconcrete-/paving/cement-modified-soils-(cms).

[18] K. Waelbers, "Immobilization of $\mathrm{Cr}$ VI in concrete structures using PowerCem," Bateman Materials Limited Reg. No. 1956/01084/06, 2006.

[19] U. Sandberg, J. Kragh, L. Goubert et al., Optimization of Thin Asphalt Layers-State-of-the-Art Review, Swedish National Road and Transport Research Institute (VTI), Danish Road Institute (DRI) \& Belgian Road Research Centre (BRRC), 2011.

[20] P. M. O. Owende, A. M. Hartman, S. M. Ward, M. D. Gilchrist, and M. J. O'Mahony, "Minimizing distress on flexible pavements using variable tire pressure," Journal of Transportation Engineering, vol. 127, no. 3, pp. 254-262, 2001.

[21] British Standards Institution, "Cement: composition, specifications and conformity criteria for common cements," EN 197-1, British Standards Institution, London, UK, 2000.

[22] British Standard Institute, "Testing hardened concrete. Compressive strength of test specimens," Tech. Rep. EN 12390-3, British Standard Institute, London, UK, 2009.

[23] British Standard Institute, "Testing hardened concrete. Flexural strength of concrete," Tech. Rep. BS 1881-109 \& BS 1881-118, British Standard Institute, London, UK, 2003.

[24] K. Sobolev and A. Amirjanov, "Application of genetic algorithm for modeling of dense packing of concrete aggregates," Construction and Building Materials, vol. 24, no. 8, pp. 1449-1455, 2010.

[25] B. Babić, "Relationships between mechanical properties of cement stabilized materials," Materials and Structures, vol. 20, no. 6, pp. 455-460, 1987.

[26] E. Otte, Factors Affecting the Behavior of Cement Treated Layers in Pavements, 1978, http://trid.trb.org/view.aspx?id=147339.

[27] B. S. Bhogal, P. S. Coupe, J. Davies, and L. M. Fendukly, "Dynamic flexure tests of soil-cement beams," Journal of Materials Science Letters, vol. 14, no. 4, pp. 302-304, 1995.

[28] K. Sobhan and B. M. Das, "Durability of soil-cements against fatigue fracture," Journal of Materials in Civil Engineering, vol. 19, no. 1, pp. 26-32, 2007.
[29] W. W. Little, “Tensile fracture and fatigue of cement-stabilized soil," Transportation Engineering, vol. 113, pp. 26-45, 1987.

[30] Eurocode 2: Design of concrete structures British Standards Institution, BS EN, 1992.

[31] S. Popovics, "A numerical approach to the complete stress-strain curve of concrete," Cement and Concrete Research, vol. 3, no. 5, pp. 583-599, 1973.

[32] W. S. Adaska and D. R. Luhr, "Control of reflective cracking in cement stabilized pavements," in Proceedings of the 5th International RILEM Conference, Limoges, France, May 2004.

[33] K. P. George, Minimizing Cracking in Cement-Treated Materials for Improved Performance, PCA Portland Cement Association, Skokie, Ill, USA, 2002.

[34] K. P. George, "Shrinkage characteristics of soil-cement mixtures," Tech. Rep. 255, Highway Research Record, Washington, DC, USA, 1968.

[35] R. K. M. Bhandari, "Shrinkage of cement treated mixtures," Journal of the Australian Road Research Board, vol. 5, no. 3, pp. 3-21, 1973.

[36] K. P. George, "Shrinkage characteristics of soil-cement mixtures," Highway Research Record 255, Transportation Research Board, Washington, DC, USA, 1973.

[37] H. Nakayama and R. L. Handy, "Factors influencing shrinkage of soil-cement," Highway Research Record 86, Transportation Research Board, Washington, DC, USA, 1965.

[38] Y.-H. Cho and K.-W. Lee, "Development of cement-treated base material for reducing shrinkage cracks," Transportation Research Record, vol. 1952, no. 1, pp. 134-143, 2006.

[39] S. A. Shihata and Z. A. Baghdadi, "Long-term strength and durability of soil cement," Journal of Materials in Civil Engineering, vol. 13, no. 3, pp. 161-165, 2001. 

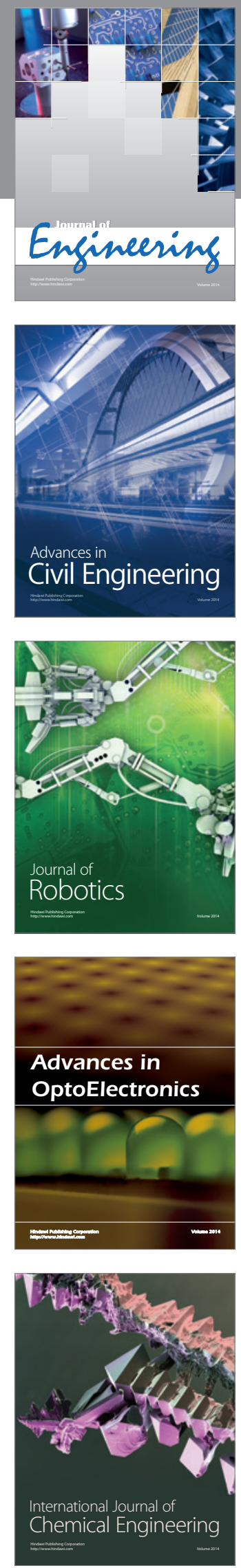

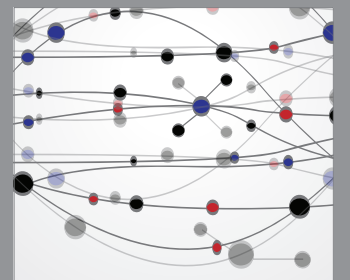

The Scientific World Journal
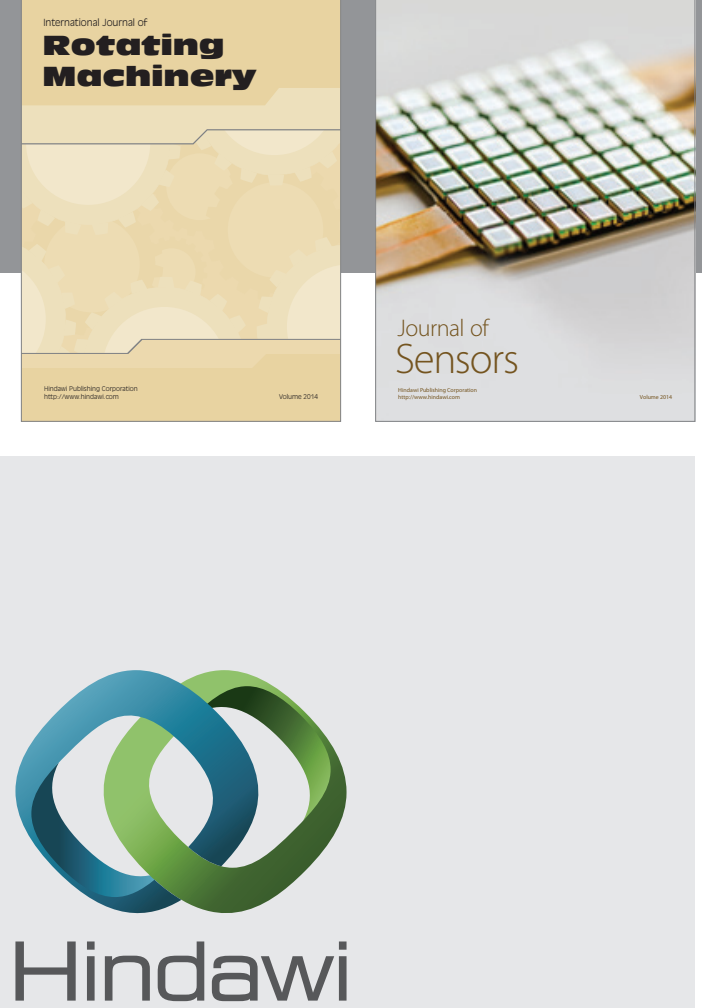

Submit your manuscripts at http://www.hindawi.com
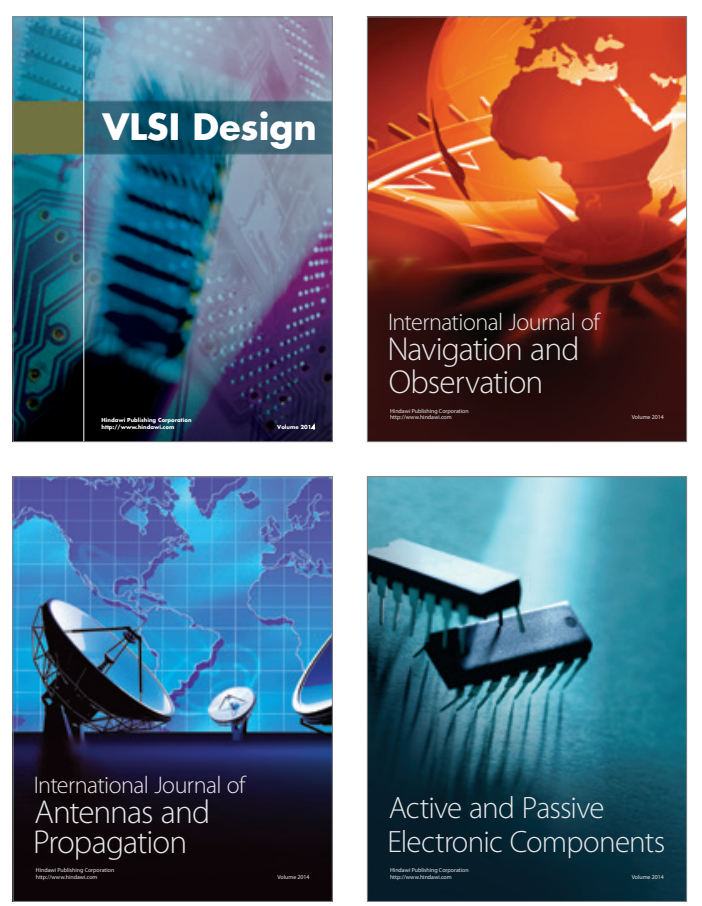
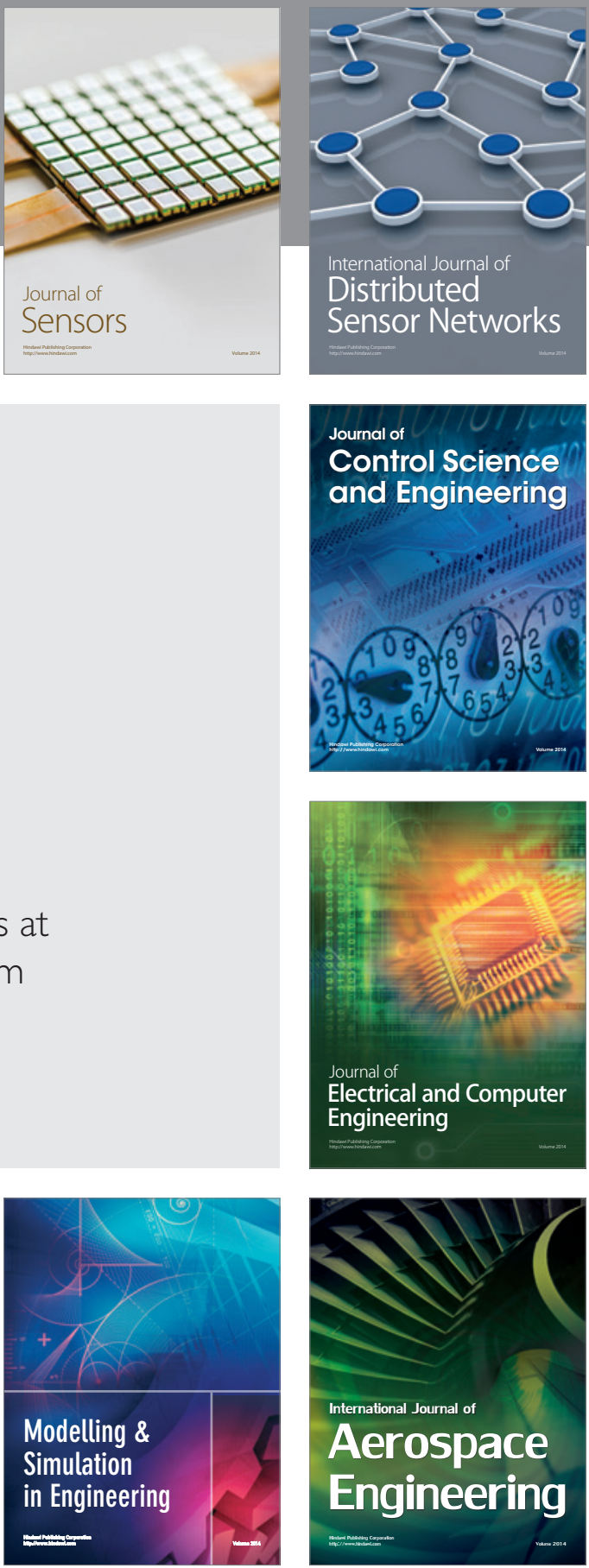

Journal of

Control Science

and Engineering
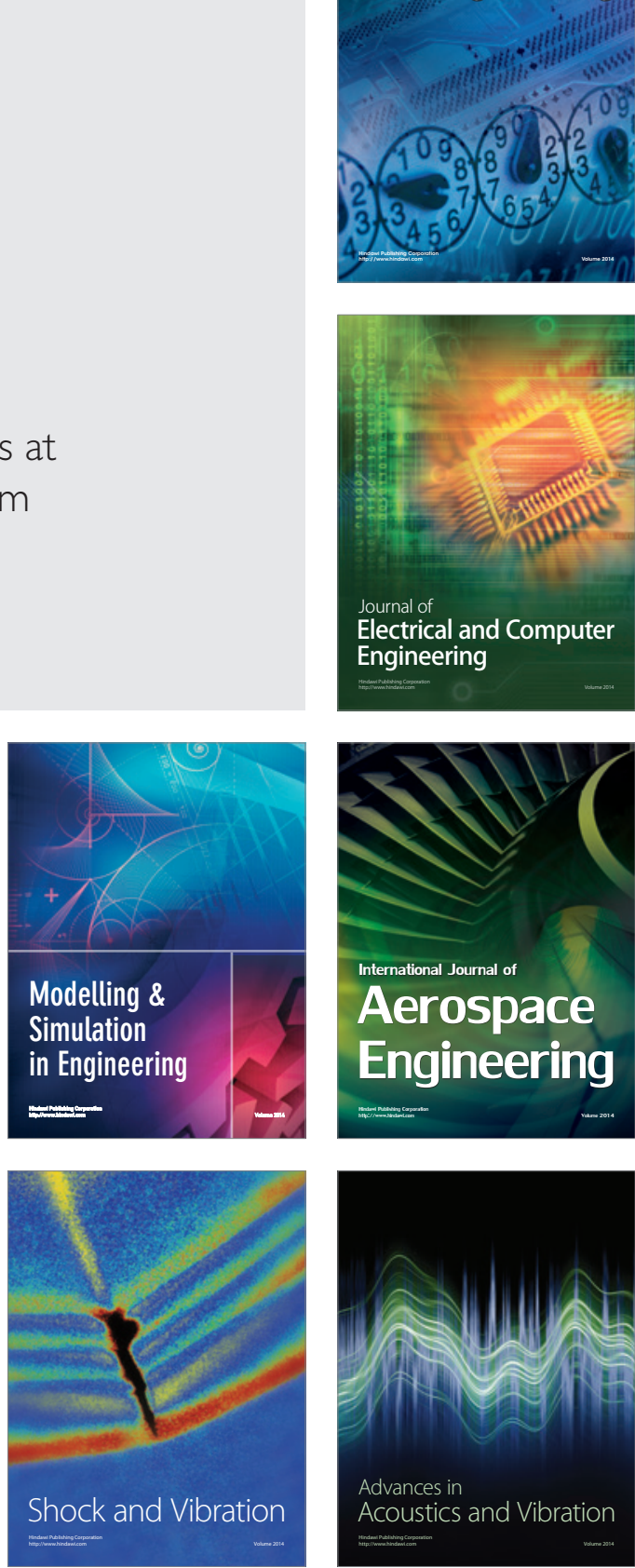